\title{
Investigation of Single Pass Welding of Thick AH36 Steel Plates in a Square Groove Butt Joint Configuration During AC-GMAW
}

\author{
Adeel Ikram*, Ahmad Raza** and Hyun Chung*, $\dagger$ \\ *Department of Naval Architecture and Ocean Engineering, Chungnam National University, Daejeon, 34134, Korea \\ **Department of Nuclear and Quantum Engineering, KAIST, Daejeon, 34141, Korea \\ †Corresponding author : hchung@cnu.ac.kr \\ (Received February 5, 2020 ; Revised March 25, 2020 ; Accepted April 21, 2020)
}

\begin{abstract}
This study was performed to investigate the AC-GMAW process for joining of $6 \mathrm{~mm}$ to $8 \mathrm{~mm}$ thick AH36 steel plates in a single pass welding using a square groove butt joint configuration. A broad range of experiments was conducted at different welding speeds and joint gaps. Initially, a suitable setting of welding speed and the joint gap was determined based on the results of penetration depth and the gap bridging ability of the welded joints. Then, the quality of the selected welded joints was examined by hardness and tensile testing. Microstructure and fractured surface analysis were carried out using scanning electron microscopy (SEM) to examine the surface morphology. Based on the experimental findings, recommendations were made for selecting suitable input welding parameters for the welding of plates up to $8 \mathrm{~mm}$ using the AC-GMAW process.
\end{abstract}

Key Words : AC-GMAW, Penetration depth, HAZ, Tensile testing, Thick plates, AH36, Fracture toughness

\section{Introduction}

Welding of thick steel plates is a challenging task in many industries such as shipbuilding, nuclear and power plants ${ }^{1,2}$. Different welding techniques are employed to join thick steel plates like laser beam welding, submerged arc welding (SAW) and multi-pass gas metal arc welding (GMAW) ${ }^{3)}$. The laser beam welding process provide good penetration capabilities and low distortion but at the expense of high capital costs, precise fit-up requirements, extensive groove preparation and indoor welding limitations ${ }^{4-6}$. The SAW delivers high material deposition and good penetration capabilities but the amount of heat supplied to the base metal is quite $\operatorname{high}^{7}$. As a result, there is a large heat affected zone (HAZ) and a great post-weld distortion ${ }^{8,9)}$. C. Shen ${ }^{10)}$ reported the estimated cost of correcting the post weld distortion and it found to be as high as 30\% of the total manufacturing cost. Moreover, welds produced by SAW are limited to flat and horizontal welding position ${ }^{11)}$. The multi-pass GMAW process in direct current (DC) mode is employed to weld thick plates. However, high number of welding passes considerably increase the production time and cost. Compared to conventional GMAW, alternating current gas metal arc welding (AC-GMAW) is an advanced variant of GMAW process. It can be a better substitute for joining of thick plates owing to its low heat input to the workpiece and high material deposition rate capabilities ${ }^{12)}$. AC-GMAW pulse works in two domains i.e. the electrode-positive (EP) and the electrode-negative (EN) domain. The arc stability is controlled by EP domain whereas high material deposition is governed by EN domain of the pulse $^{13)}$. D.D. Harwig ${ }^{14)}$ analyzed melting rates of the process for different current waveforms. They concluded that the melting rate and the size of the metal droplet are influenced by the changing behavior of the current pulse. A.S. Nascimento et al. ${ }^{15)}$ used four different waveforms with varying EN ratios to determine the suitable pulsing parameters that can provide better arc and metal transfer stability. L.O. Vilarinho et al. ${ }^{16)}$ developed a methodology for the selection of AC-GMAW process parameters to reduce the arc and metal transfer 
instabilities. H.J. Park et al. ${ }^{17)}$ analyzed the weld characteristics of dissimilar metals. They concluded that AC-GMAW process provided the good gap-bridging ability for dissimilar weld joints. A. Scotti and L.S. Monteiro $^{18)}$ evaluated a methodology for the input parameters selection for AC-MIG/MAG process. N. Arif and H. Chung ${ }^{19)}$ measured the drop sizes using both simulation and experimental techniques for different wires of steel. D.V. Kiran et al. ${ }^{20)}$ analyzed the behavior of the molten metal droplet and the welding arc at different EN ratios. K. Kim and H. Chung ${ }^{21)}$ calculated the wire melting rate coefficients and developed wire melting equation based on the arc physics principles. D.D. Harwig et al. ${ }^{22)}$ carried out the welding of $1.8 \mathrm{~mm}$ steel lap joint with a gap of $1.8 \mathrm{~mm}$ using AC-GMAW and pulsed GMAW. He showed that AC-GMAW provided up to $300 \%$ higher welding speeds and up to $47 \%$ less heat input as compared to pulsed GMAW process. In the beginning, AC-GMAW was applied on thin steel plates but subsequently further research work was done to extend AC-GMAW applicability for welding of thick steel plates. Regarding thick steel plate welding, the process was firstly investigated by N. Arif and $\mathrm{H}$. Chung $^{23)}$. They observed finger-like penetration at high values of current and EN ratio. A. Ikram and H. Chung ${ }^{24)}$ further researched the work and conducted an experimental study on a $5 \mathrm{~mm}$ thickness of steel plate. They proposed a current setting of $250 \mathrm{~A}$ and EN ratio of $50 \%$ for welding of steel plates where the weld joints exhibited both deep penetration and sound weld quality. However, review of the available literature has revealed that the limited findings have been reported regarding the welding of thick steel plates with the AC-GMAW process. The selection of optimum welding parameters is quite essential in welding because it determines the quality of the welded joints. Therefore, the selection of optimal welding parameters for the thicker steel plate for AC-GMAW process needs to be sought. In this paper, the work is carried out to weld $6 \mathrm{~mm}$ to $8 \mathrm{~mm}$ thick steel plates in a single pass welding. The influence of welding travel speed and joint gap on weld characteristics is investigated experimentally. Based on the experimental findings, recommendations have been made on the selection of suitable welding parameters for welding of plates up to $8 \mathrm{~mm}$ using AC-GMAW process.

\section{Experimental procedure}

\subsection{Materials}

High-strength low-alloy (HSLA) material AH36 was used as a base metal. AH36 is largely used in shipbuilding for ship's hull structure. Three different thicknesses of plates i.e. $6 \mathrm{~mm}, 7 \mathrm{~mm}$ and $8 \mathrm{~mm}$ were used. The chemical composition of the base metal and filler wire (ER-70S) have been shown in Table 1 and Table 2 respectively. A steel filler wire of diameter $1.2 \mathrm{~mm}$ was used in the experimentation.

\subsection{Welding experimental set-up}

Before carrying out the actual welding tests, proper alignment of two steel plates was carried out to ensure an accurate gap between joints using the magnetic clampers. The dimensions of the steel plates were $250 \mathrm{~mm}$ $\times 125 \mathrm{~mm} \times 6 \sim 8 \mathrm{~mm}$ (thickness). A fixed gap of $1 \mathrm{~mm}$ or $2 \mathrm{~mm}$ was maintained depending upon the welding conditions. The butt-joint was made in square groove configuration and ends of plates were connected with tack welding. The welding position used in our study was flat $1 \mathrm{G}$. The yield strength (YS) of the workpiece was $290 \mathrm{MPa}$ whereas it had tensile strength (TS) of $485 \mathrm{MPa}$. The steel filler wire had the YS and TS of $450 \mathrm{MPa}$ and $540 \mathrm{MPa}$ respectively.

For conducting the welding tests, OTC-Daihen manufactured power supply DW-300 was used. The workpiece was travelled relative to the welding torch with a specific welding travel speed. A constant contact to workpiece distance (CTWD) of $25 \mathrm{~mm}$ was used. An average electrode extension of $18 \mathrm{~mm}$ was kept in all experimental runs. A mixture of shielding gases i.e. ar-

Table 1 Chemical composition of AH-36

\begin{tabular}{|c|c|c|c|c|c|c|c|c|c|c|}
\hline $\mathrm{C}$ & $\mathrm{Si}$ & $\mathrm{P}$ & $\mathrm{Mn}$ & $\mathrm{Cr}$ & $\mathrm{S}$ & $\mathrm{Mo}$ & $\mathrm{Ni}$ & $\mathrm{Cu}$ & $\mathrm{V}$ & $\mathrm{Fe}$ \\
\hline 0.18 & 0.50 & 0.035 & 0.90 & 0.20 & 0.035 & 0.08 & 0.40 & 0.35 & 0.04 & Balance \\
\hline
\end{tabular}

Table 2 Chemical composition of filler wire (ER-70S)

\begin{tabular}{|c|c|c|c|c|c|c|c|c|c|c|}
\hline $\mathrm{C}$ & $\mathrm{Si}$ & $\mathrm{P}$ & $\mathrm{Mn}$ & $\mathrm{Cr}$ & $\mathrm{S}$ & $\mathrm{Mo}$ & $\mathrm{Ni}$ & $\mathrm{Cu}$ & $\mathrm{V}$ & $\mathrm{Fe}$ \\
\hline $0.06 \sim 0.15$ & 0.450 .75 & 0.025 & 1.401 .85 & 0.15 & 0.035 & 0.15 & 0.15 & 0.50 & 0.03 & Balance \\
\hline
\end{tabular}



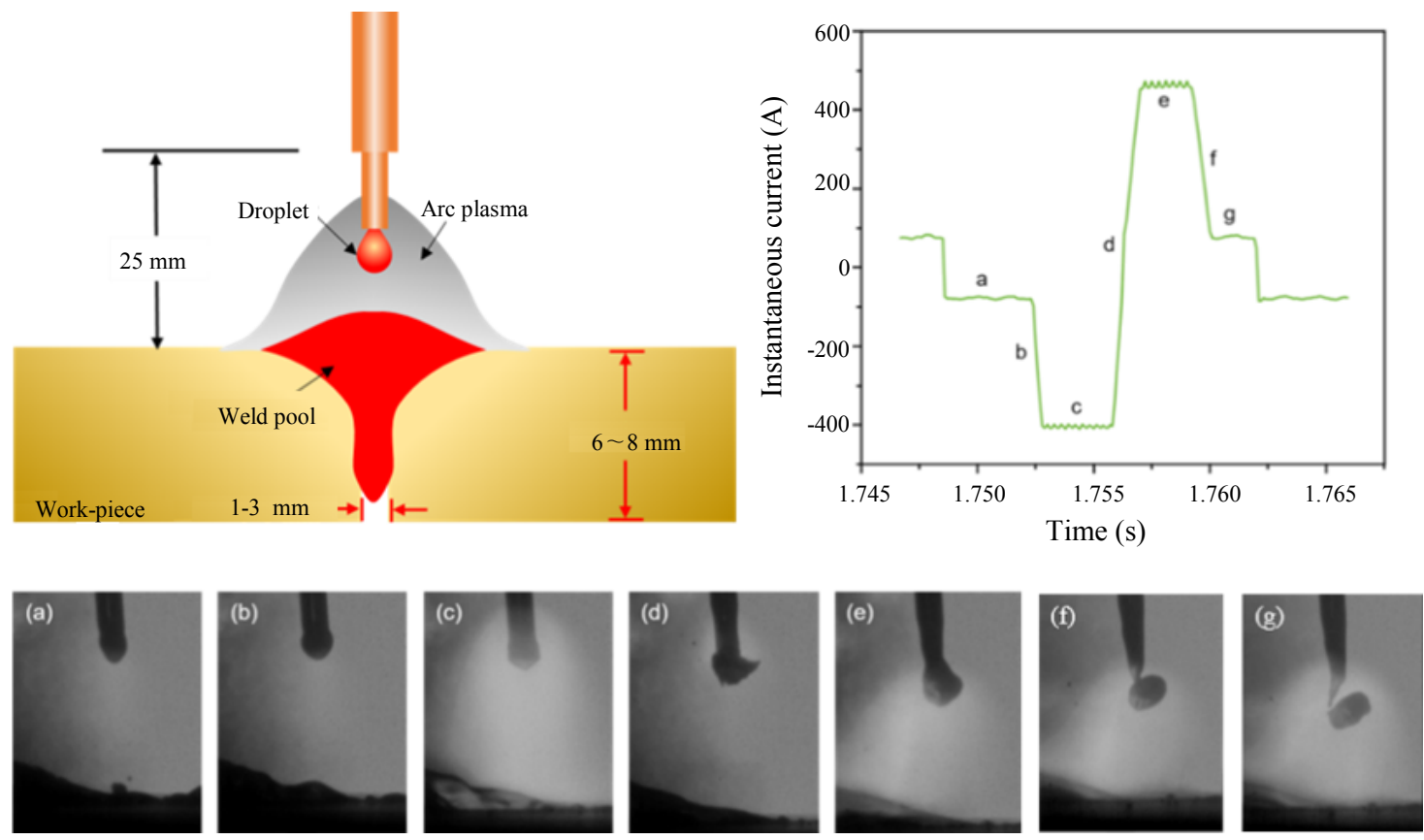

Fig. 1 Schematics of the welding process

gon (Ar) and carbon dioxide $\left(\mathrm{CO}_{2}\right)$ with a ratio of $80 \% \mathrm{Ar}-20 \% \mathrm{CO}_{2}$ was provided using a gas mixing unit. A controlled amount of flow-rate of $18 \mathrm{~L} / \mathrm{min}$ was supplied. In order to visualize the molten metal droplet transfer and arc behavior, a Miro-eX4 Mono camera manufactured by Phantom was used. It recorded a video with 10,000 fps. A CAVILUX pulsed diode laser light source manufactured by High Speed Imaging Inc. was used as a back-light system to clearly visualize the mode of transfer, droplet transfer behavior and generation of spatters if present.

The welding was performed at a constant current and EN ratio of $250 \mathrm{~A}$ and $50 \%$ respectively. These constant parameters were selected based on the previously published literature ${ }^{24)}$. However, the welding speed was varied from $4 \mathrm{~mm} / \mathrm{s}$ to $16 \mathrm{~mm} / \mathrm{s}$. The joint gap of $1 \mathrm{~mm}$ to $2 \mathrm{~mm}$ was set depending on the experimental run. The experimental schematics of the process is represented in Fig. 1. It showed AC-GMAW current waveform and associated high-speed metal transfer and arc behavior. The high-speed video was synchronized with the current waveform at a different time interval to better understand the flow of metal transfer.

\section{Results and Discussion}

\subsection{Effect of welding speed}

While maintaining a joint gap of $2 \mathrm{~mm}$, welding experiments were carried out. The welding travel speed was varied from $4 \mathrm{~mm} / \mathrm{s}$ to $16 \mathrm{~mm} / \mathrm{s}$ with an increment of $2 \mathrm{~mm} / \mathrm{s}$. The selective results are presented in Fig. 2 . Fig. 2 (a) shows the optimum welding speeds at different thicknesses of plate. The error bar represents the standard deviation. In Fig. 2 (b) the dotted line indicates HAZ and the solid line indicates fusion line. It was found that for a $6 \mathrm{~mm}$ thick plate, there was a good gap bridging irrespective of the welding speed and the molten metal was penetrated deep into the root at a welding travel speed ranging from $4 \mathrm{~mm} / \mathrm{s}$ to $14 \mathrm{~mm} / \mathrm{s}$. This is because of the sufficient heat input supplied to the workpiece. The HAZ was found to be $52 \mathrm{~mm}^{2}, 47 \mathrm{~mm}^{2}$ and $42 \mathrm{~mm}^{2}$ at a welding speeds of $10 \mathrm{~mm} / \mathrm{s}, 12 \mathrm{~mm} / \mathrm{s}$ and $14 \mathrm{~mm} / \mathrm{s}$ respectively. It was found that the optimum welding speed was obtained in the range between $12 \mathrm{~mm} / \mathrm{s}$ to $14 \mathrm{~mm} / \mathrm{s}$ where the welding joints exhibited better gap bridging and complete penetration. For 7 $\mathrm{mm}$ thick plate, the optimum welding speed was obtained in the range between $8 \mathrm{~mm} / \mathrm{s}$ to $10 \mathrm{~mm} / \mathrm{s}$ where the joint exhibited the good side fusion and deep penetration with suitable bead width, reinforcement height and gap bridging. However, when welding travel speed was increased above $10 \mathrm{~mm} / \mathrm{s}$, an incomplete filling of the molten metal and lower penetration depth was observed. This is because of the fact that less heat input was supplied owing to high welding speed. The HAZ was found to be $57 \mathrm{~mm}^{2}$ and $53 \mathrm{~mm}^{2}$ at a welding speeds of $8 \mathrm{~mm} / \mathrm{s}$ and $10 \mathrm{~mm} / \mathrm{s}$ respectively. For $8 \mathrm{~mm}$ plate, welding speed in the range between $6 \mathrm{~mm} / \mathrm{s}$ to $8 \mathrm{~mm} / \mathrm{s}$ provided optimum material transfer rate with complete 


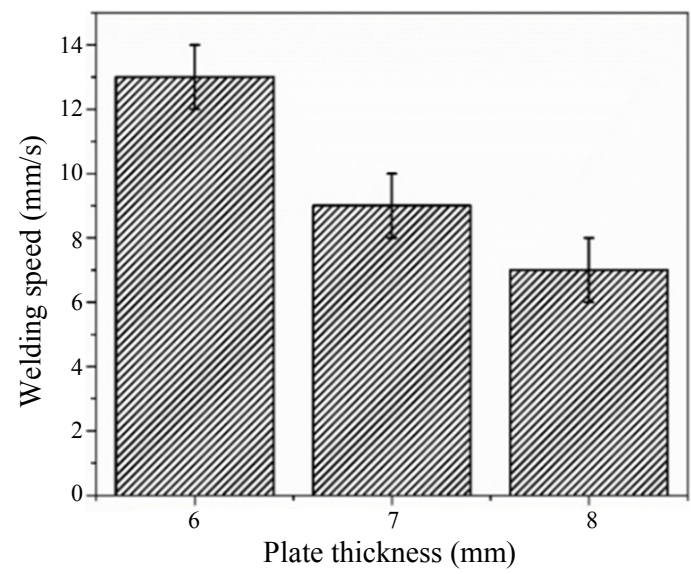

(a)

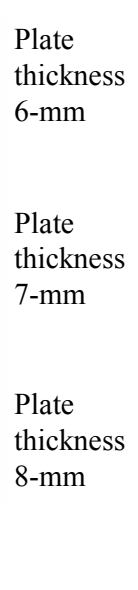

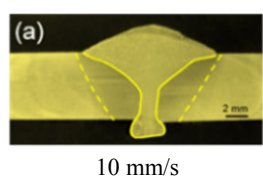
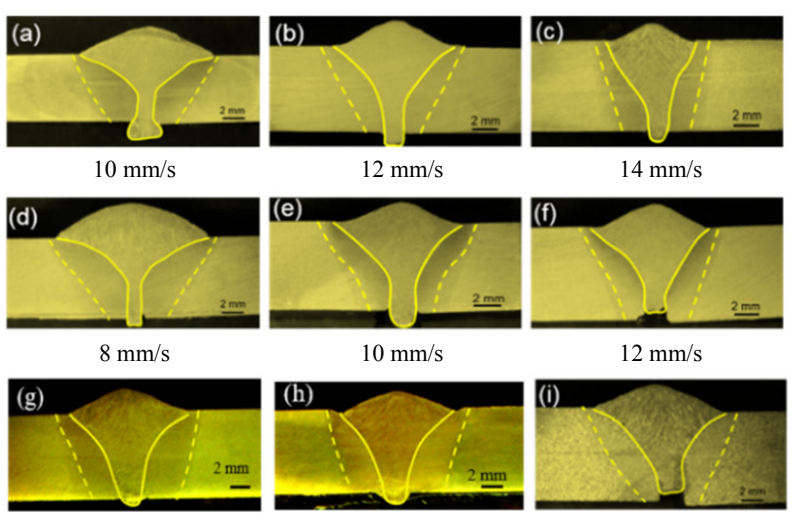

$6 \mathrm{~mm} / \mathrm{s}$

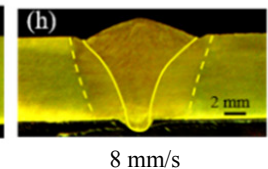

(b)

Fig. 2 Welding joints and their penetration depths at different welding speeds

penetration depth. The HAZ was found to be $72 \mathrm{~mm}^{2}$ and $64 \mathrm{~mm}^{2}$ for a welding speed of $6 \mathrm{~mm} / \mathrm{s}$ and $8 \mathrm{~mm} / \mathrm{s}$ respectively.

\subsection{Effect of joint gaps}

Based on the optimum welding speeds range determined in section 3.1, joint gap was reduced to $1 \mathrm{~mm}$ and welding experiments were performed. At a joint gap of $1 \mathrm{~mm}$, there was a good gap bridging but less penetration depth as shown in Fig. 3. In Fig. 3 (b) the dotted line indicates the HAZ and the solid line indicates the fusion line. Fig. 3 (a) shows the penetration depth at different welding speed. It was found at a joint gap of $1 \mathrm{~mm}$ there was a lack of complete penetration of molten metal across the thickness irrespective of the thickness of the plate, resultant in under filing at the root side. This is because of the fact that reducing the

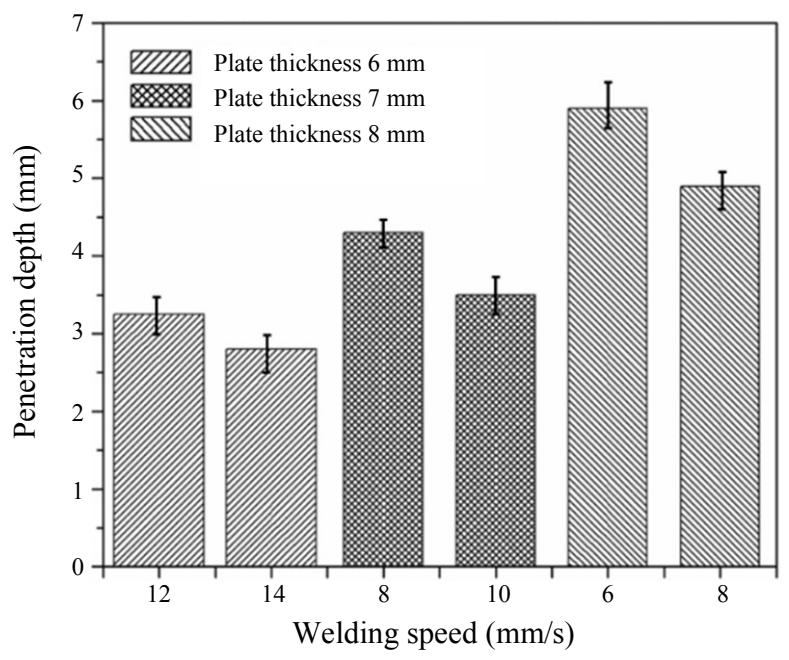

(a) joint gap from $2 \mathrm{~mm}$ to $1 \mathrm{~mm}$, the molten metal could not penetrate deep into the root owing to the narrow gap between the two welded plates. The reduction in gap hindered the smooth flow of molten metal deep into the root resulted in high reinforcement height and less penetration depth. The maximum penetration was measured $3.2 \mathrm{~mm}$ at a welding speed of $12 \mathrm{~mm} / \mathrm{s}, 4.3$ $\mathrm{mm}$ at a welding speed of $8 \mathrm{~mm} / \mathrm{s}$ and $5.9 \mathrm{~mm}$ at a welding speed of $6 \mathrm{~mm} / \mathrm{s}$ for $6 \mathrm{~mm}, 7 \mathrm{~mm}$ and $8 \mathrm{~mm}$ thickness of plate respectively. Based on the research findings, it can be concluded that a joint gap of $2 \mathrm{~mm}$ should be maintained to fill the groove area with the molten metal otherwise reducing the joint gap may cause incomplete filling of molten metal.

\subsection{Microstructure Analysis}

The microstructure analysis of three distinctive zones
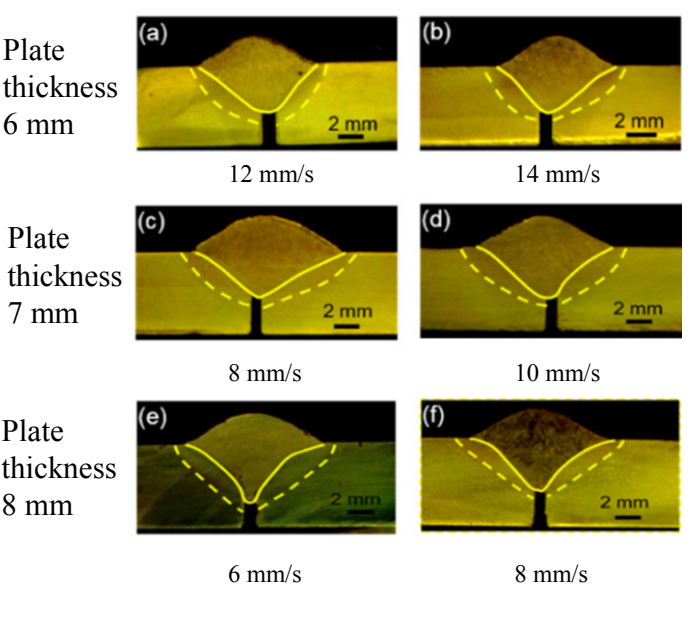

$12 \mathrm{~mm} / \mathrm{s}$

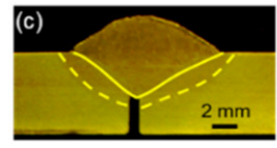

$14 \mathrm{~mm} / \mathrm{s}$

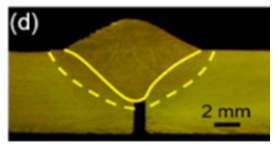

$8 \mathrm{~mm} / \mathrm{s}$

$10 \mathrm{~mm} / \mathrm{s}$

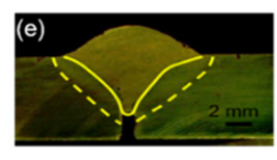

$6 \mathrm{~mm} / \mathrm{s}$

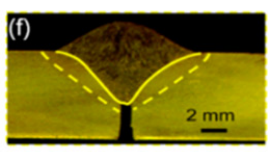

$8 \mathrm{~mm} / \mathrm{s}$

(b)

Fig. 3 Penetration depth at joint gap of $1 \mathrm{~mm}$ with optimum welding speeds 

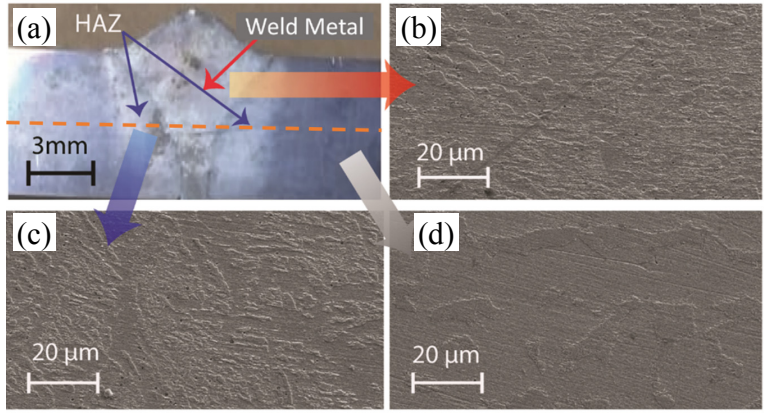

Fig. 4 (a) Cross-section of weld specimen (plate thickness: $6 \mathrm{~mm}$, welding speed: $12 \mathrm{~mm} / \mathrm{s}$, joint gap: $\mathrm{mm}$ ) (b) microstructure of weld metal, (c) microstructure of HAZ, and (d) microstructure of base metal

including weld metal, HAZ, and base metal was performed using scanning electron microscopy (SEM) SU5000 manufactured by HITACHI, Japan. The transverse cross-section of the weld specimen was obtained through wire electrical discharge machining process. Fig. 4. shows the images obtained from the samples of $6 \mathrm{~mm}$ thickness, and $12 \mathrm{~mm} / \mathrm{s}$ welding speed at a joint gap of $2 \mathrm{~mm}$. Fig. 4 (a) is an image taken from the cross section of the welded joint which is distinctively differentiating the weld metal from HAZ, and HAZ from base metal. Fig. 4 (b) is highlighting the microstructure of the weld metal, and the fine grain size distribution is evident in the image. The fine grain size was resultant from the high cooling rate. This is be- cause that the temperature of the weld pool was relatively high compared to the base metal close to the weld. Furthermore, Fig. 4 (c) is exhibiting an image taken from the HAZ. The HAZ is showing slightly larger grain size than from the weld metal but still finer than base metal. The decrease in grain size of HAZ has happened due to the phase transformation during the heating cycle and then cooling of the molten weld pool under ambient condition during the reverse phase transformation cycle. The microstructure of the base metal is shown in Fig. 4 (d), which is displaying significantly larger grains as compared to the HAZ, which is primarily due to prior welding larger grain size and no heat effect on the base metal during the welding. The similar trend was observed with the other thicknesses of plates at their optimum parameters condition. The different phase constituents of the welded joint were identified using optical microscopy as shown in Fig. 5. The microstructures after polishing and macro-etching (3\% Nital), the cross sections of the joints were examined. In the weld metal, the phase constituents were consisted of Widmanstätten ferrite and grain boundary ferrite. Small pits were also observed in the weld metal area. The HAZ showed fine grains. It was found that the HAZ had an average grain size of $14 \mu \mathrm{m}$. The decrease of the grain size was due to the high cooling rates. The microstructure of the base metal was cosnsited of the layer laminated distribution of bright ferrite and dark pearlite with grains oriented in rolling direction.
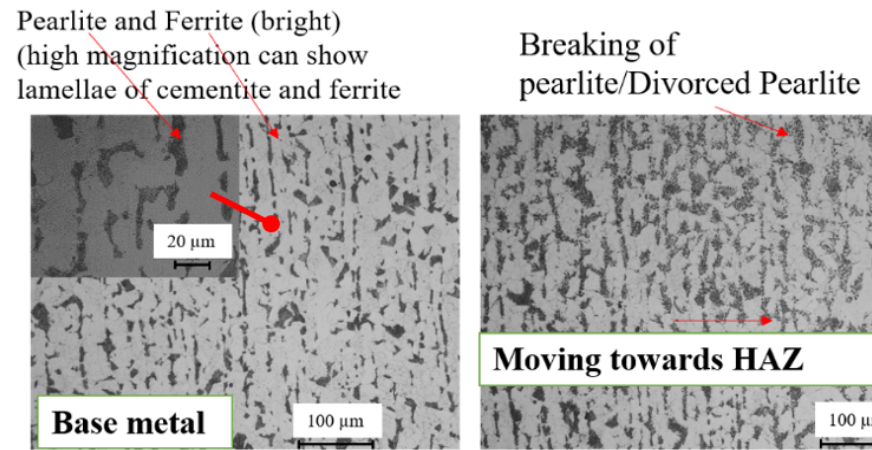

Breaking of pearlite/Divorced Pearlite

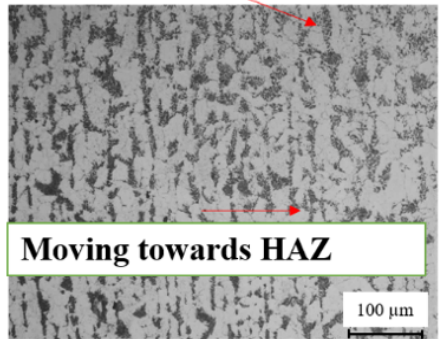

Fine grain structure as cooling rate was very high

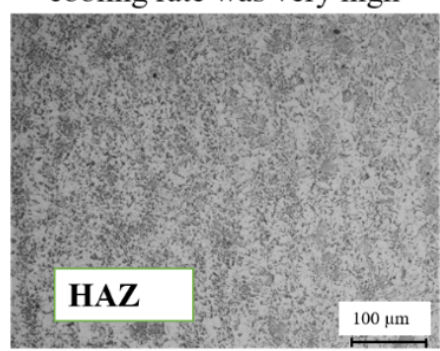

Pitting corrosion (pits)

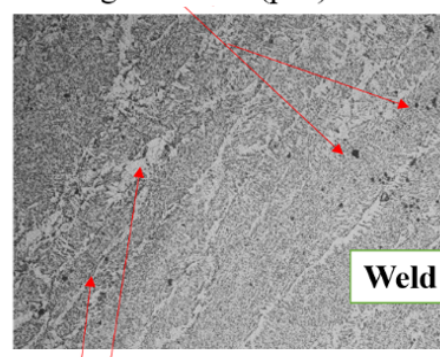

Grain boundary ferrite
Widmanstätten ferrite

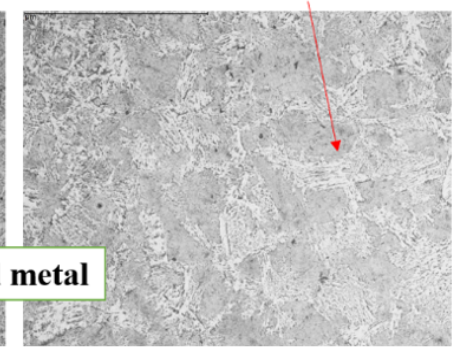

nis 3

Fig. 5 Exhibiting various zones like base metal, HAZ and weld metal 


\subsection{Hardness testing}

Microhardness testing has been employed and the results are displayed in Fig. 6. A Micro Vickers hardness tester (Mitutoyo, Aurora, IL, USA) was used to measure the hardness of the welded samples. The dotted line in Fig. 4 (a) shows the hardness measurement line. The hardness distribution was measured at a centerline passing between the top and bottom of the base plate. To exhibit the variation in hardness relative to the indentation area, each curve has three distinct regions where the HAZ is highlighted by the shaded region. By evaluating the data obtained from the $6 \mathrm{~mm}$ plates at welding speeds of $10 \mathrm{~mm} / \mathrm{s}, 12 \mathrm{~mm} / \mathrm{s}$ and $14 \mathrm{~mm} / \mathrm{s}$, it is evident that the hardness is showing an increasing trend from base metal to HAZ and fusion zone. The increase in grain size is quite understandable with the grain sizes of various regions. As the base metal has a coarse grain size, it is showing lower hardnesheetsss value i.e. 160 HV. Similarly, the decrease in grain size from base metal to HAZ, and HAZ to weld metal caused the substantial enhancement in the hardness value of the various region. Given the finer grain size in the weld metal, it is showing the highest values of the hardness i.e. 225 HV. It is clearly evident that the weld metal area at a lower speed of $10 \mathrm{~mm} / \mathrm{s}$ is substantially larger than the weld metal area at a higher speed of $14 \mathrm{~mm} / \mathrm{s}$. Likewise, the HAZ is also inversely varying with the welding speed. Although the weld speeds are lower in the welding of other plates, a similar trend can be observed in both other plates with a thickness of $7 \mathrm{~mm}$ and $8 \mathrm{~mm}$. Based on hardness data, it can be concluded that the higher the speed is better for the grain size and hardness distribution according to the distnace from the center. Moreover, the hardness of the welded specimen depends on number of parameters such as width of the weld metal and HAZ.

\subsection{Tensile testing}

Based on the selection of optimum parameters, the tensile tests were performed and the results are represented in Fig. 7. The samples were prepared according to the ASTM E8/E8M standard ${ }^{25)}$. INSTRON universal testing machine 5583 with maximum $150 \mathrm{kN}$ load cell capacity was used. The crosshead speed was kept at 2.8
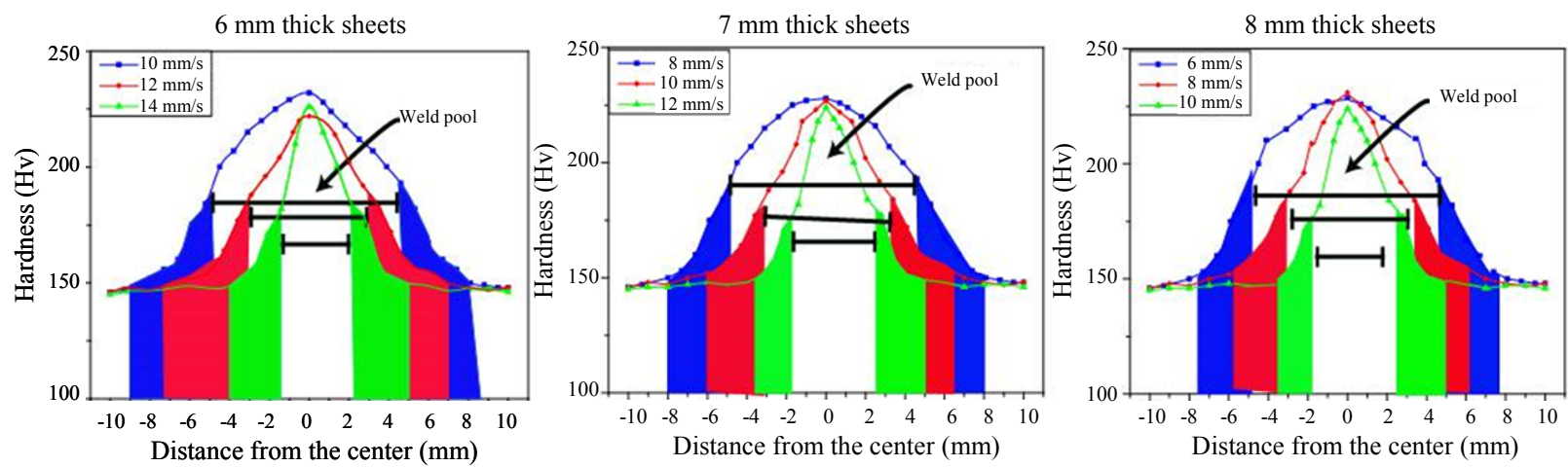

Fig. 6 The hardness of (a) $6 \mathrm{~mm}$ thick plate, welding speed: $10 \mathrm{~mm} / \mathrm{s}, 12 \mathrm{~mm} / \mathrm{s}, 14 \mathrm{~mm} / \mathrm{s}$, (b) $7 \mathrm{~mm}$ thick plate, welding speed: $8 \mathrm{~mm} / \mathrm{s}, 10 \mathrm{~mm} / \mathrm{s}, 12 \mathrm{~mm} / \mathrm{s}$, and (c) $8 \mathrm{~mm}$ thick plate, welding speed: $6 \mathrm{~mm} / \mathrm{s}, 8 \mathrm{~mm} / \mathrm{s}, 10 \mathrm{~mm} / \mathrm{s}$

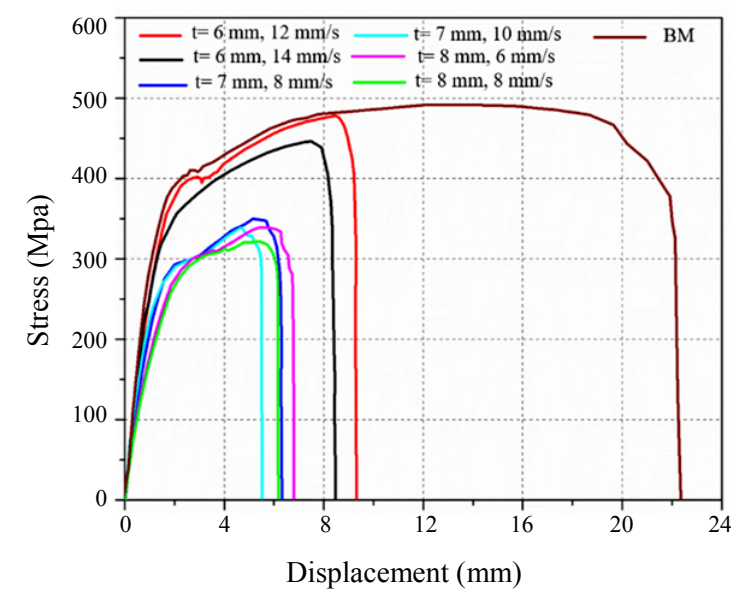

(a)

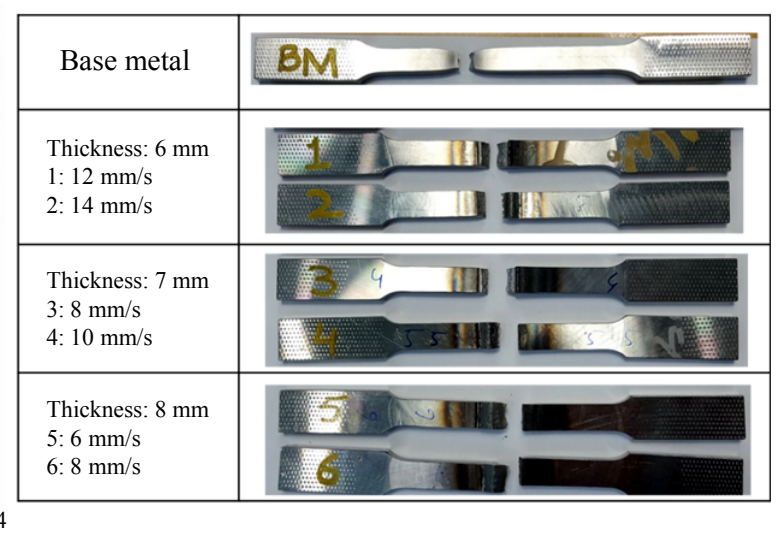

(b)

Fig. 7 (a) Tensile tests results at optimum welding parameters (b) The fractured position of the tensile tested joints 
$\mathrm{mm} / \mathrm{min}$ during the test. From the findings, it can be concluded that for $6 \mathrm{~mm}$ steel plate, the TS i.e. 465 $\mathrm{MPa}$ was achieved at a welding speed of $12 \mathrm{~mm} / \mathrm{s}$ which is very close to the TS i.e. $485 \mathrm{MPa}$ of base metal. The TS of the welded sample was found to be $96.87 \%$ of the base metal. However, a decrease in TS i.e. $445 \mathrm{MPa}$ was measured at a welding speed of 14 $\mathrm{mm} / \mathrm{s}$ with the same thickness of the plate. The percentage elongation was found to be $4.5 \%$ and $4.1 \%$ at a welding speed of $12 \mathrm{~mm} / \mathrm{s}$ ad $14 \mathrm{~mm} / \mathrm{s}$ respectively. Similarly, for $7 \mathrm{~mm}$ plate, a TS of $349 \mathrm{MPa}$ and 337 $\mathrm{MPa}$ were recorded at a welding speed of $8 \mathrm{~mm} / \mathrm{s}$ and $10 \mathrm{~mm} / \mathrm{s}$ respectively which is $72.70 \%$ and $70.20 \%$ respectively of the base metal. The percentage elongation was found to be $3.1 \%$ and $2.8 \%$ at a welding speed of $8 \mathrm{~mm} / \mathrm{s}$ ad $10 \mathrm{~mm} / \mathrm{s}$ respectively. Similarly, in the case of $8 \mathrm{~mm}$ plate, TS of the $338 \mathrm{MPa}$ was measured at a welding speed of $6 \mathrm{~mm} / \mathrm{s}$ which is $70.41 \%$ of the base metal. The percentage elongation was measured as 3.2 $\%$. At a welding speed of $8 \mathrm{~mm} / \mathrm{s}$, TS was found to be $322 \mathrm{MPa}$ which is $67.08 \%$ of the base metal. The percentage elongation was found to be $3.1 \%$. From the above research findings, it can be concluded that the weld joints exhibited sound weld quality. However, with the increase in thickness, the TS of the weld joints decreases. Moreover, it was found that all the welded samples were fractured at the fusion line as shown in Fig. 7 (b).

\subsection{Fracture behavior}

The typical morphology of the fractured surface samples obtained from tensile tests was examined by SEM. In Fig. 8 (a), fractured surface of base metal showed a complete ductile fracture having small and uniform spherical dimples since it underwent an appreciable amount of plastic deformation. This is because of the
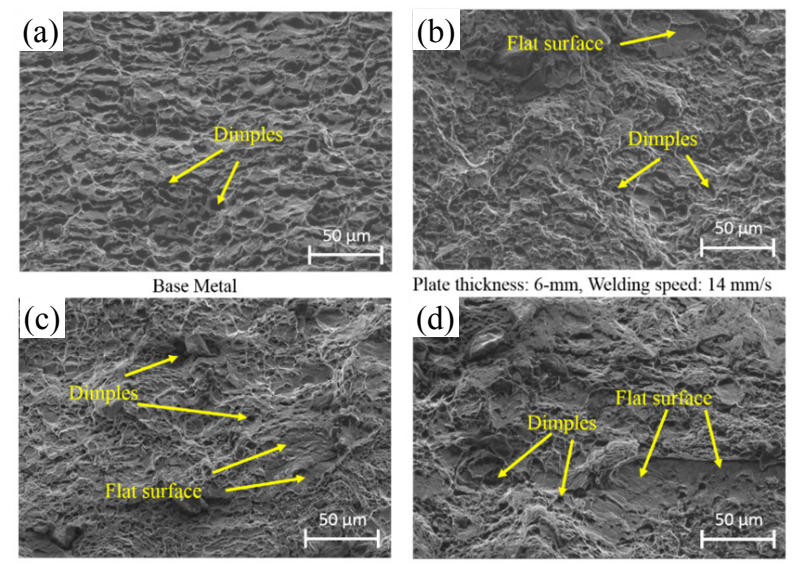

Plate thickness: 7-mm, Welding speed: $10 \mathrm{~mm} / \mathrm{s}$

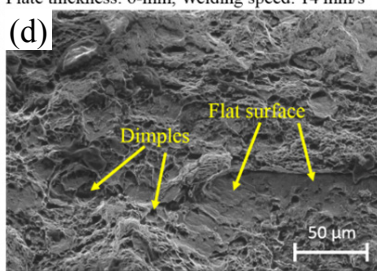

Fig. 8 SEM micrographs of tensile fractured surfaces large grain size of the base metal. As slip lines are confined to the grain boundaries, the larger amount of slip can occur thus providing the greater ductility. Fig. 8 (b) shows the fractured surface for a $6 \mathrm{~mm}$ plate welded joint at a travel speed of $14 \mathrm{~mm} / \mathrm{s}$. The sample surface showed a ductile fracture. However, ductility of the sample was decreased compared to the base metal. This can be attributed to the relatively fine grain size of the welded joint in the fusion zone and HAZ. The finer grain size, the lesser is the ductility because the slip is restricted. Fig. 8 (c) and Fig. 8 (d) show the fractured surface for $7 \mathrm{~mm}$ and $8 \mathrm{~mm}$ and thick plate at a welding speed of $10 \mathrm{~mm} / \mathrm{s}$ and $8 \mathrm{~mm} / \mathrm{s}$ respectively. The fractographic examination revealed both the dimples and flat surfaces. The ductility of both the samples was decreased compared to the base metal. All the specimen underwent plastic deformation before fracture.

\section{Conclusions}

The following conclusions were drawn from the study; 1) It is recommended that for welding of thick plates, the welding travel speed should be maintained in between the range of $12 \mathrm{~mm} / \mathrm{s}$ to $14 \mathrm{~mm} / \mathrm{s}$ for $6 \mathrm{~mm}$ plate, $8 \mathrm{~mm} / \mathrm{s}$ to $10 \mathrm{~mm} / \mathrm{s}$ for $7 \mathrm{~mm}$ plate and $6 \mathrm{~mm} / \mathrm{s}$ to 8 $\mathrm{mm} / \mathrm{s}$ for $8 \mathrm{~mm}$ thick steel plate. A joint gap of $2 \mathrm{~mm}$ should be used for welding of plates with average welding current of $250 \mathrm{~A}$ and $50 \% \mathrm{EN}$ ratio.

2) The microstructure of the weld metal showed the fine grain size distribution. The weld metal was consisted of Widmanstätten ferrite and grain boundary ferrite. However, the HAZ showed the slightly large grain size than from the weld metal but still finer than the base metal.

3) The hardness of welded metal and HAZ was higher than the hardness of the base metal due to the local hardening phenomenon happened in the weld metal and in the HAZ.

4) The welded joint exhibited good tensile properties for all thicknesses of plates.

5) The fractured surface analysis of the welded specimen showed a decrease in ductility compared to the base metal. This can be attributed to the relatively fine grain size of the welded joint in the fusion zone and HAZ.

\section{Acknowledgement}

This work was supported by the research fund of Chungnam National University.

ORCID: Adeel Ikram: http://orcid.org/0000-0002-3258-9409

ORCID: Ahmad Raza: http://orcid.org/0000-0003-4450-2451

ORCID: Hyun Chung: https://orcid.org/0000-0001-9749-8666 


\section{References}

1. M. M. Atabaki, N. Yazdian, J. Ma, R. Kovacevic, High power laser welding of thick steel plates in a horizontal butt joint configuration, Opt. Laser Technol. 83 (2016) $1-12$.

http://dx.doi.org/10.1016/j.optlastec.2016.03.016

2. F. Vollertsen, S. Grünenwald, M. Rethmeier, A. Gumenyuk, U. Reisgen, S. Olschok, Welding thick steel plates with fiber lasers and GMAW, Weld. World, 54(3-4) (2010) R62-R70. https://doi.org/10.1007/BF03263489

3. A. Ikram, N. Arif, H. Chung, Design of an induction system for induction assisted alternating current gas metal arc welding, J. Mater. Process. Technol. 231 (2016) 162170 .

https://doi.org/10.1016/j.jmatprotec.2015.12.015

4. B. Acherjee, Hybrid laser arc welding: State-of-art review, Opt. Laser Technol. 99 (2018) 60-71. https://doi.org/10.1016/j.optlastec.2017.09.038

5. E. Bayer, B. Brenner, R. Poprawe, Hybrid laser welding techniques for enhanced welding efficiency, Proceeding of the Laser Materials Processings Conference ICALEO '96, Detroit, USA, (1996) 157-166.

https://doi.org/10.2351/1.5059055

6. T. Ishide, S. Tsubota, M. Watanabe, Latest MIG, TIG, arc-YAG laser hybrid welding systems for various welding products, Proceedings of 1st International Symposium on High-Power Laser Macroprocessing (SPIE 2003), Osaka, Japan, (2002) 347-352.

https://doi.org/10.1117/12.497771

7. J. Aaanie, I.N.A. Oguocha, S. Yannacopoulos, Effect of submerged arc welding parameters on microstructure of SA516 steel weld metal, Canadian Metall. Quart. 51(1) (2013) 48-57.

https://doi.org/10.1179/000844311X13117643274794

8. A. Joarder, S.C. Saha, A.K. Ghose, Study of submerged arc weld metal and heat-affected zone microstructures of a plain carbon steel, Weld. J. Suppl. Res. 70(6) (1991) 141-146.

https://app.aws.org/wj/supplement/WJ_1991_06_s141.pdf

9. C.S. Lee, R.S. Chandel, H.P. Seow, Effect of Welding Parameters on the Size of Heat Affected Zone of Submerged Arc Welding. Mater. Manuf. Processes. 15(5) (2000) 649-666.

https://doi.org/10.1080/10426910008913011

10. C. Shen, Master of Engineering Thesis, Low distortion welding for shipbuilding industry, School of Mechanical, Materials and Mechatronic Engineering, University of Wollongong, Wollongong, Australia (2013). https://ro.uow.edu.au/theses/3892/

11. A. Yadav, A. Ghosh, A. Kumar, Experimental and numerical study of thermal field and weld bead characteristics in submerged arc welded plate, J. Mater. Process. Technol. 248 (2017) 262-274. https://doi.org/10.1016/j.jmatprotec.2017.05.021

12. J. E. Talkington, Master of Science Thesis, Variable polarity gas metal arc welding, Graduate School of The Ohio State University, Columbus, Ohio, USA, (1998). http://rave.ohiolink.edu/etdc/view?acc_num $=$ osu 1130 352747

13. S. Harada, T. Ueyama, T. Mita, T. In-nami, M. Ushio, The state-of-the-art of AC-GMAW process in Japan, Proceedings Conference IIW, Doc. XIII-1589-1599 (1999). https://ci.nii.ac.jp/naid/10030149343/

14. D. D. Harwig, Ph D dissertation, Arc behaviour and metal transfer of the VP-GMAW process, School of Industrial and Manufacturing Science, Cranfield University, Bedfordshire, United Kingdom, (2003). http://dspace.lib.cranfield.ac.uk/handle/1826/11375

15. A. S. Nascimento, D. B. Fernandes, C. A. Mota, L. O. Vilarinho, Methodology for determination of parameters for welding MIG with variable polarity, Weld. Int. 23 (2008) 473-480. https://doi.org/10.1080/09507110802543435

16. L. O. Vilarinho, A. S. Nascimento, D. B. Fernandes, C.A.M. Mota, Methodology for parameter calculation of VP-GMAW. Weld. J. 88 (2009) 92s-98s. https://app.aws.org/wj/supplement/WJ_2009_04_s92.pdf

17. H. J. Park, S. Rhee, M. J. Kang, D. C. Kim, Joining of steel to aluminum alloy by AC pulse MIG welding, Mater. Trans. 50(9) (2009) 2314-2317. https://doi.org/10.2320/matertrans.M2009105

18. A. Scotto, L. S. Monteiro, A methodology for parameterization of the AC MIG/MAG process, Soldag. Insp. São Paulo, 17(3) (2012) 271-277. http://dx.doi.org/10.1590/S0104-92242012000300011

19. N. Arif, H. Chung, Alternating current-gas metal arc welding for application to thin sheets. J. Mater. Process. Technol. 214 (2014) 1828-1837.

https://doi.org/10.1016/j.jmatprotec.2014.03.034

20. D. V. Kiran, J. Cheon, N. Arif, H. Chung, S. J. Na, Threedimensional finite element modeling of pulsed AC gas metal arc welding process, Int. J. Adv. Manuf. Technol. 86,(2016) 1453-1474.

https://doi.org/10.1007/s00170-015-8297-2

21. K. Kim, H. Chung, Wire melting rate of alternating current gas metal arc welding, Int. J. Adv. Manuf. Technol. 90(5-8) (2016) 1253-1263.

https://doi.org/10.1007/s00170-016-9384-8

22. D. D. Harwig, J. E. Dierksheide, D. Yapp and S. Blackman, Arc behavior and melting rate in the VP-GMAW process, Weld. J. 85 (2006) 52-62. https://app.aws.org/wj/supplement/WJ_2006_03_s52.pdf

23. N. Arif, H. Chung, Alternating current-gas metal arc welding for application for application to thick plates, $J$. Mater. Process. Technol. 222 (2015) 75-83. https://doi.org/10.1016/j.jmatprotec.2015.02.041 
24. A. Ikram, H. Chung, The effect of EN ratio and current on microstructural and mechanical properties of weld joined by AC-GMAW on square groove butt joints, Appl. Sci. 7, 261 (2017). https://doi.org/10.3390/app7030261

25. ASTM E8/E8M Standard Test Methods for Tension Testing of Metallic Materials.

https://www.astm.org/Standards/E8 